\title{
Avaliação da Aceitabilidade do Software Educacional Sr. Bohr como Ferramenta Lúdica para o Ensino-Aprendizagem
}

\author{
Breno A. L. Andrade ${ }^{1}$, Pablo F. Matos ${ }^{1}$, Viviane L. Carvalho ${ }^{1}$, \\ Wdson C. Santos', Assayá F. Santos ${ }^{2}$ \\ ${ }^{1}$ Bacharelado em Sistemas de Informação - Instituto Federal de Educação, Ciência e \\ Tecnologia da Bahia (IFBA) - Vitória da Conquista - BA - Brasil \\ ${ }^{2}$ Licenciatura em Química - Instituto Federal de Educação, Ciência e Tecnologia da \\ Bahia (IFBA) - Vitória da Conquista - BA - Brasil \\ breno.lessa.andrade@gmail.com, pablofmatos@ifba.edu.br, \\ vivicarvalho6@gmail.com, wdsoncostalifba.edu.br, assayaquimicalgmail.com
}

\begin{abstract}
The educational software Sr. Bohr discusses in their questions different contents accomplished in the chemistry discipline and aspects of everyday life related to these. This teaching tool is designed to assist in the teaching-learning process of chemistry, exploring characteristic elements of the electronic games like the fun and competitiveness. This paper proposes an analysis from experiments conducted with students and teachers in order to assess the acceptability and the interaction level of the software. The authors verified that Sr. Bohr is a promising web application as a facilitator for the students to learn through challenge, reward and visual stimuli, beyond fun.

Resumo. O software educacional Sr. Bohr aborda em suas questões diferentes conteúdos trabalhados na disciplina de química e aspectos do cotidiano relacionados a estes. Esta ferramenta didática tem o objetivo de auxiliar no processo de ensino-aprendizagem de química, explorando elementos característicos dos jogos eletrônicos, como a diversão e a competitividade. Para avaliar a aceitabilidade e o nivel de interação do software, este artigo propõe uma análise a partir de experimentos realizados com discentes e docentes. Constata-se assim, que o Sr. Bohr é uma aplicação web promissora como meio facilitador para os discentes aprenderem por meio do desafio, da recompensa e dos estímulos visuais, além da diversão.
\end{abstract}

\section{Introdução}

$\mathrm{O}$ acesso às tecnologias vem crescendo em largas proporções, tornando um bem comum as diversas ferramentas que facilitam o desenvolvimento de atividades do dia a dia. Comunicação, sistemas de segurança e transações bancárias são exemplos de tarefas que fazem um grande uso da informatização. Com toda essa aplicabilidade, um ponto importante é o uso dessas ferramentas como um auxílio no processo de ensino e aprendizagem, seja com o intuito de facilitar o acesso à informação ou de estimular os estudantes de uma maneira mais atrativa [1].

O uso das ferramentas computacionais propicia flexibilidade e criatividade, fazendo o discente pesquisar, encorajando o pensamento criativo e estimulando a intuição [2]. Segundo [3], os jogos educativos estão sendo adotados cada vez mais por professores para tornar as aulas mais interessantes e divertidas. Esse método de ensino através do lúdico a partir dos jogos tem por objetivo construir um novo comportamento 
e, consequentemente, um novo perfil de estudante, que tenha no aprender o prazer e o desafio proporcionados pelos jogos.

Os jogos são caracterizados como um tipo de recurso didático educativo que pode ser utilizado em momentos distintos como na apresentação de um conteúdo, ilustração de aspectos relevantes ao conteúdo, avaliação de conteúdos já desenvolvidos e como revisão ou síntese de conceitos importantes do conteúdo [4]. Através das Tecnologias da Informação e Comunicação é possível desenvolver softwares que, com direcionamentos educacionais, trazem os aspectos das atividades lúdicas com a estratégia adequada para o auxílio à obtenção do conhecimento de forma prazerosa, agregando maior valor à diversão, que vinha apenas como passatempo.

Guimarães e Robaina [5] afirmam que o ensino de química é, em geral, tradicional, centralizando-se na simples memorização e repetição de nomes, fórmulas e cálculos, totalmente desvinculados do dia a dia e da realidade em que os estudantes se encontram. Assim, os mesmos propõem uma mudança desse método através da inserção de atividades lúdicas como os jogos, e ainda definem: Atividade lúdica é todo e qualquer movimento que tem como objetivo produzir prazer quando de sua execução, divertindo o praticante.

A partir deste contexto, pretende-se avaliar a aceitabilidade do software educacional Sr. Bohr como ferramenta lúdica no processo ensino-aprendizagem. O restante deste artigo está estruturado como segue. Na Seção 2, são resumidos os trabalhos correlatos, enquanto na Seção 3, é apresentada a metodologia de desenvolvimento do software educacional. Na Seção 4, são detalhadas as características do Sr. Bohr. Na Seção 5 é descrita a realização do experimento com discentes e docentes, e na Seção 6, são apresentadas as Conclusões e os Trabalhos Futuros.

\section{Trabalhos Correlatos}

Há softwares educacionais que promovem aprendizagem por meio do envolvimento lúdico, uma vez que este tipo de ferramenta encontra-se em ascensão devido à inserção tecnológica no ambiente escolar. Carbópolis [6], Titulando [7], Kinble [8] e Myquímica [9] são exemplos desse tipo de software.

Alguns trabalhos encontrados na literatura, no contexto de jogos envolvendo o lúdico, apresentam como os mesmos foram avaliados. Ludo Químico [10] e Bingo Químico [11] avaliaram o aprendizado aplicando questionário com docentes e discentes. O primeiro concluiu que o jogo obteve êxito como ferramenta educativa, ressaltando que o mesmo promoveu entusiasmo, estímulo e aprendizagem. O segundo observou que o jogo foi bem aceito pelos discentes, possibilitando que a aula teórica se tornasse mais atrativa, divertida e interessante.

Outrossim, pode-se citar como exemplos de jogos educativos voltados ao ensino de química: Dados Orgânicos [12], Trilha da Química [13], Baralho ácido-base [14] e QUIZmica [15].

\section{Metodologia de Desenvolvimento}

A metodologia de desenvolvimento do software educacional é composta por quatro etapas: (1) Seleção da Tecnologia, (2) Elaboração da Base de Dados, (3) Implementação e (4) Validação. 


\subsection{Seleção da Tecnologia}

Na Etapa 1 é escolhida a linguagem HTML5 [16] como tecnologia de desenvolvimento que, ao ser implementado por meio de um Game Engine (motor de jogo) apropriado, oferece grandes vantagens, a saber: A linguagem é aberta e tem o seu desenvolvimento por um grande conjunto de empresas de tecnologia; O produto é compatível com todas as plataformas do mercado e é dispensada a instalação de plugins adicionais, já que os próprios navegadores oferecem suporte nativo, o que torna mais eficiente a utilização dos recursos computacionais e evita que incompatibilidades de plataforma ocorram; E a adição de funcionalidades é realizada com mais facilidade, uma vez que não é necessário implementar uma versão para cada plataforma.

\subsection{Elaboração da Base de Dados}

Na Etapa 2 é realizada a elaboração da base de dados com perguntas/respostas a cerca dos temas geradores com assuntos relacionados à química. As questões do software possuem uma linguagem simples e com poucas palavras, o que resulta em um layout simples e aumenta o nível de dificuldade. Essas questões são armazenadas em uma estrutura lógica a fim de serem utilizadas de forma dinâmica no software desenvolvido. A estrutura escolhida para criação da base de dados é o padrão XML (eXtensible Markup Language), que é uma recomendação da W3C [17] para criar linguagens de marcação, sendo de simples manuseio e fácil consulta por meio do game engine. A elaboração da base de dados é realizada por discentes de Licenciatura em Química, bolsistas do projeto PIBID (Programa Institucional de Bolsa de Iniciação à Docência), e um docente da mesma área, por apresentar conhecimentos específicos na área de atuação do jogo.

\subsection{Implementação}

Na Etapa 3 é implementado o software educacional com os recursos gráficos e visuais (e.g., layout, botões, textos e cenários) a partir da base de dados elaborada na Etapa 2. Como consequência da escolha do HTML5 na Etapa 1, é utilizada duas ferramentas para dar suporte na criação do jogo: a primeira é o game engine Construct 2 [18], opção mais indicada por atender ao critério de seleção e ao mesmo tempo por dispensar conhecimentos prévios de desenvolvimentos de jogos, reduzindo a necessidade de uma grande equipe; a segunda ferramenta é o Inkscape [19] selecionado para construção de toda parte gráfica do jogo, sendo escolhido principalmente pelos conhecimentos prévios por parte dos integrantes do grupo. O armazenamento das respostas é realizado por meio da linguagem de programação dinâmica PHP [20] que tem a função de processar as respostas e solicitar ao Sistema Gerenciador de Banco de Dados (SGBD) o armazenamento das mesmas. O SGBD utilizado é o MySQL [21].

\subsection{Validação}

Por fim, na Etapa 4, são analisados os resultados obtidos por meio da aplicação de um questionário, que contém questões diversas com a finalidade de obter a opinião dos discentes e docentes sobre a experiência da utilização, para que seja avaliada a aceitabilidade do software e o aproveitamento percebido pelos discentes. 


\section{Sr. Bohr}

O software educacional Sr. Bohr (Figura 1-a), desenvolvido com base no jogo Roda das Esmeraldas [22], tem como objetivo oferecer ao usuário um desafio do tipo perguntas e respostas relacionadas aos conteúdos de química e aspectos do cotidiano [23]. O nome Sr. Bohr foi adotado para o software devido à utilização do modelo atômico no jogo, em referência a contribuição da compreensão desse modelo pelo físico Niels Bohr (18851962). A plataforma do jogo é WEB, o que possibilita certo grau de facilidade em seu uso, já que não é necessário realizar instalações. É possível utilizá-lo em qualquer navegador com suporte à tecnologia HTML5 por meio da seguinte URL (LocalizadorPadrão de Recursos) http://srbohr.esy.es/.

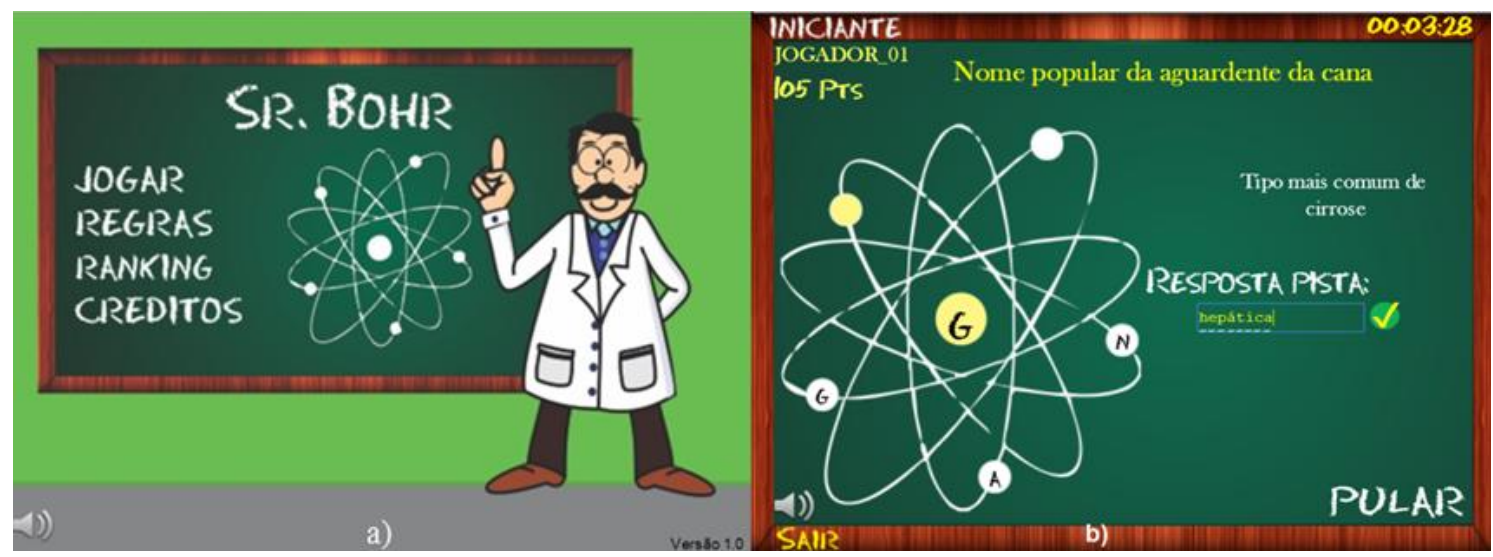

Figura 1. Sr. Bohr. a) Menu Principal. b) Tela Enigma/Pista Fonte. Próprio autor

\subsection{Definição: Pista e Enigma}

Cada "Pista" corresponde a um elétron representado no modelo atômico, ficando visível ao clicar em qualquer um deles (Figura 1-b). O número de letras ao responder a "Pista" é igual ao número de traços que aparece no campo "Resposta Pista". Ao descobrir a resposta da "Pista", uma letra aparece em destaque no elétron correspondente, de forma que, ao descobrir a resposta para todas as "Pistas", o campo "Resposta Enigma" fica visível. As letras destacadas em cada um dos elétrons, quando organizadas na sequência correta, formam a resposta do enigma.

A resposta do "Enigma" tem um número de letras igual ao número de elétrons presentes na representação do modelo atômico (Figura 1-b). Esta resposta é formada por um conjunto de letras, geradas a partir das respostas das "Pistas", que não estão organizadas em sequência. Assim, o campo "Resposta Enigma" somente fica visível depois que todas as respostas das "Pistas" são descobertas.

\subsection{Base de Dados}

As questões da base de dados são criadas a partir do conceito de temas geradores. Cada questão contém um enigma que corresponde à pergunta principal e é baseada em um tema gerador. Um enigma é formado por um número de pistas equivalente ao número de letras da resposta do enigma. As pistas requerem conhecimentos de química e de aspectos do cotidiano, e estão relacionadas ao tema gerador presente no enigma. Por exemplo, "Gás essencial à sobrevivência humana" é um enigma, cuja resposta é oxigênio (tema gerador deste enigma). Na Tabela 1 encontram-se exemplos de pistas 
para este enigma. As letras sublinhadas e em negrito formam a resposta para o enigma. As respostas das pistas não estão numa sequência lógica, para evitar que a resposta do enigma seja imediata.

Ao todo foram elaboradas 30 (trinta) questões, sendo cada uma delas formada por um enigma e um conjunto de pistas (variando em quantidade de 4 até 8 pistas). Todas as questões que compõem a base de dados seguem este mesmo raciocínio. Essas questões foram desenvolvidas com a ajuda de duas discentes do curso de Licenciatura em Química, envolvidas neste projeto, com o auxílio de um docente da mesma área.

Tabela 1. Pistas com suas respectivas respostas para o tema gerador "oxigênio"

\begin{tabular}{l|l}
\multicolumn{1}{c|}{ Pistas } & \multicolumn{1}{c}{ Resposta } \\
\hline Substância formada por átomos de um mesmo elemento. & simples \\
\hline Denominação das filas verticais da tabela periódica. & famílias \\
\hline Nome do grupo 16 da tabela periódica. & calcogênios \\
\hline Estado físico mais desorganizado da matéria. & gasóso \\
\hline Capacidade de um mesmo elemento formar mais de uma substância simples. & alotropia \\
\hline Ligação química formada a partir do compartilhamento de elétrons. & covalente \\
\hline Gás nobre localizado no quinto período da tabela periódica. & $\underline{\text { xenônio }}$ \\
\hline Substância que possui apenas ligações covalentes. & mole $\underline{\text { ecular }}$ \\
\hline
\end{tabular}

Fonte. Próprio autor

A partir do estudo de substâncias químicas é possível gerar a discussão de vários conteúdos relacionados à química, os quais são abordados nas demais questões. No exemplo apresentado na Tabela 1, a partir do tema gerador "oxigênio" é apresentado questões que discorrem sobre assuntos, tais como, classificação das substâncias (simples ou compostas), organização da tabela periódica, alotropia, estados físicos da matéria e ligações químicas.

As questões são armazenadas e organizadas em uma estrutura a fim de serem utilizadas de forma dinâmica. A estrutura utilizada para este fim é a estrutura de dados XML. A validação das respostas é feita de modo que a palavra informada pelo jogador seja reconhecida em letras maiúsculas e minúsculas, com ou sem acentos. Na Figura 2 encontra-se um exemplo da estrutura XML utilizada. Pode-se observar que para um determinado tema gerador há a pergunta e a resposta do enigma, assim como as perguntas e as respostas das respectivas pistas. Ademais, há as letras correspondentes a resposta de cada pista. Neste exemplo há quatro pistas.

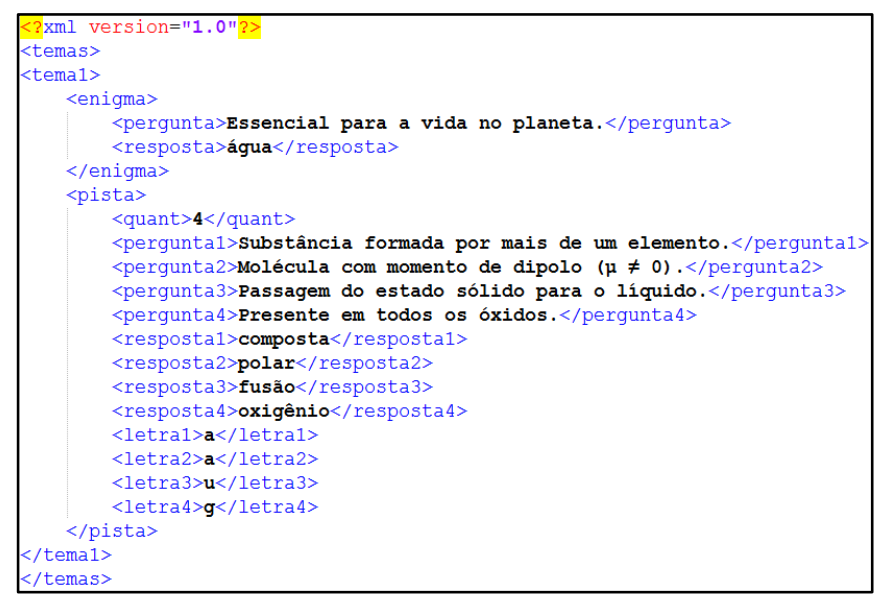

Figura 2. Estrutura XML utilizada para armazenar as perguntas e as respostas Fonte. Próprio autor 


\subsection{Classificação das Questões}

As questões são classificadas em três níveis de dificuldade: iniciante, intermediário e avançado. A fim de organizar as questões nos respectivos níveis, foi realizado um teste com um grupo de 20 (vinte) discentes do curso superior Licenciatura em Química de diferentes semestres. Para que respondessem as questões foi dado um tempo limite de 01 (uma) hora e não foi permitida a consulta a qualquer material.

A partir das respostas, foi realizado um levantamento em porcentagem de acertos em uma matriz $20 \times 30$, cuja linha representa a quantidade de avaliadores e a coluna representa a quantidade de questões. O percentual de acerto foi feito levando em consideração a quantidade de pistas respondidas corretamente. Assim, uma questão com seis pistas e somente três respondidas corretamente, obteve um percentual de $50 \%$ de acerto.

Em seguida, a partir desta matriz gerou-se uma lista com a porcentagem média de acertos. A partir desta, as 10 (dez) questões com maior percentual de acerto foram classificadas no nível iniciante; as 10 (dez) seguintes foram classificadas no nível intermediário; e o restante no nível avançado. As questões que tiveram o mesmo percentual e poderiam estar em dois níveis, por exemplo, iniciante ou intermediário, utilizou-se o seguinte critério: aquela que apresentava uma maior quantidade de pistas foi alocada no nível mais difícil e a de quantidade menor no nível mais fácil.

\subsection{Recursos}

O jogo está organizado em quatro principais recursos: nível de dificuldade, rodada, recompensa por pontuação e ranking. As questões são divididas em três níveis de dificuldade: iniciante, intermediário e avançado. Com a possibilidade de seleção do grau de complexidade das questões, o jogo proporciona ao jogador um desafio relativo ao seu conhecimento. Cada nível possui um total de $\mathbf{1 0}(\mathbf{d e z})$ enigmas, cuja resposta deve ser encontrada letra por letra a partir das respostas das pistas (Figura 1-b).

Os níveis de dificuldade são organizados em Rodadas. Assim, o jogador, no início da rodada, pode selecionar o nível de seu interesse. Uma rodada tem um total de 04 (quatro) enigmas a serem resolvidos, cada um com suas respectivas pistas. Os quatros enigmas da rodada são selecionados aleatoriamente a partir dos 10 (dez) enigmas disponíveis na base de dados para cada nível, com o controle de que nenhum enigma se repita numa mesma rodada.

Um sistema de Recompensa por Pontuação é implementado a fim de estimular o jogador: cada resposta correta da pista vale 35 (trinta e cinco) pontos; É atribuído um bônus de 220 (duzentos e vinte) pontos à resposta do enigma. O enigma só pode ser respondido depois que todas as pistas forem respondidas corretamente. Assim, a ideia é bonificar aqueles que concluírem com êxito todas as pistas. Caso o jogador não saiba responder as outras pistas, poderá pular para o próximo enigma, mas desta forma deixará de ganhar os pontos referentes às pistas não respondidas e o bônus.

O software armazena um Ranking das 05 (cinco) maiores pontuações de acordo com cada nível. O tempo é contabilizado e é usado como critério de desempate para o ranking. Não há tempo limite, já que a ideia é que a ferramenta instigue a curiosidade. Sem um limite de tempo, o discente pode realizar pesquisas para responder as questões 
e completar a rodada. No final de cada rodada, as informações do jogador, tais como, nome, pontuação, tempo e nível de dificuldade são armazenadas no SGBD.

\section{Experimento}

O objetivo deste experimento é avaliar a aceitabilidade do software Sr. Bohr no uso educacional. Este experimento foi dividido em dois momentos: Momento 1, avaliar a aceitabilidade dos discentes; Momento 2, avaliar a aceitabilidade dos docentes. No Momento 1, foi selecionada uma turma com 18 (dezoito) discentes do $3^{\circ}$ ano do Curso Técnico em Informática Integrado ao Ensino Médio para participar da avaliação do software. Os discentes utilizaram o software durante 02 (duas) horas. Os mesmos jogaram pelo menos 03 (três) rodadas, uma em cada nível de dificuldade, e ao final responderam um questionário.

No Momento 2, 04 (quatro) docentes da área de química também realizaram a avaliação do software. Para tal, o link de acesso ao jogo foi disponibilizado aos docentes, para que os mesmos fizessem uso do software, e posteriormente, respondessem um questionário manifestando sua opinião acerca do jogo. O questionário direcionado aos docentes busca verificar a opinião destes a respeito das vantagens e possibilidades do uso efetivo do Sr. Bohr como uma ferramenta didática.

\subsection{Características do Questionário}

O questionário dos discentes apresenta um total de 20 (vinte) questões. As perguntas possuem características gerais e específicas. As perguntas gerais envolvem um total de 09 (nove) questões, por exemplo: "Gosta de jogar jogos eletrônicos?" ou "Já fez uso de algum software educacional? Quantos e quais?". As perguntas específicas estão relacionadas à experiência com o software, totalizando 11 (onze) questões, a saber: "1) Sentiu-se motivado a responder todas as questões?", "2) Este jogo é adequadamente desafiador?", "3) O conteúdo do jogo é relevante para os seus interesses?", "4) $O$ design do jogo é atraente?", "5) Através do jogo foi possível relacionar diferentes conteúdos de química?", "6) As informações presentes nas regras do jogo foram suficientes para compreender o funcionamento do software?", "7) Está satisfeito porque sabe que terá oportunidades de utilizar na prática coisas que aprendeu com o jogo?", "8) O software promove momentos de cooperação elou competição entre os jogadores?", 9) O jogo é divertido?", “10) Gostaria de utilizar este software novamente?”, "11) O jogo foi eficiente para aprendizagem, em comparação com outras atividades da disciplina?".

As respostas das perguntas específicas referem-se ao quanto o avaliado concorda com a afirmativa. Para isto, são utilizados critérios que variam de uma escala de 01 (um) a 05 (cinco), onde 01 (um) significa que o avaliado discorda totalmente e 05 (cinco) concorda totalmente. O questionário direcionado aos docentes apresenta a mesma estrutura descrita anteriormente, com a ressalva de que contém 19 (dezenove) questões e apresenta um caráter mais crítico sobre o software.

\subsection{Análise dos Resultados}

No Momento 1, ao analisar a pontuação dos discentes que entraram no ranking (Figura 3), percebe-se que o nível intermediário foi o que obteve a média de maior pontuação (1.198 pontos), seguido pelos níveis iniciante (1.151 pontos) e avançado (898 pontos). 
Porém, ao analisar a média da pontuação por nível obtida por todos os discentes participantes, percebe-se que a pontuação está condizente com a classificação das questões por nível de dificuldade, feita anteriormente, a saber: níveis iniciante (708 pontos), intermediário (648 pontos) e avançado (436 pontos). Isto comprova que as questões do nível avançado apresentam um maior nível de dificuldade, sendo mais desafiadoras, e exigindo mais conhecimento e empenho por parte dos jogadores para conseguir respondê-las.

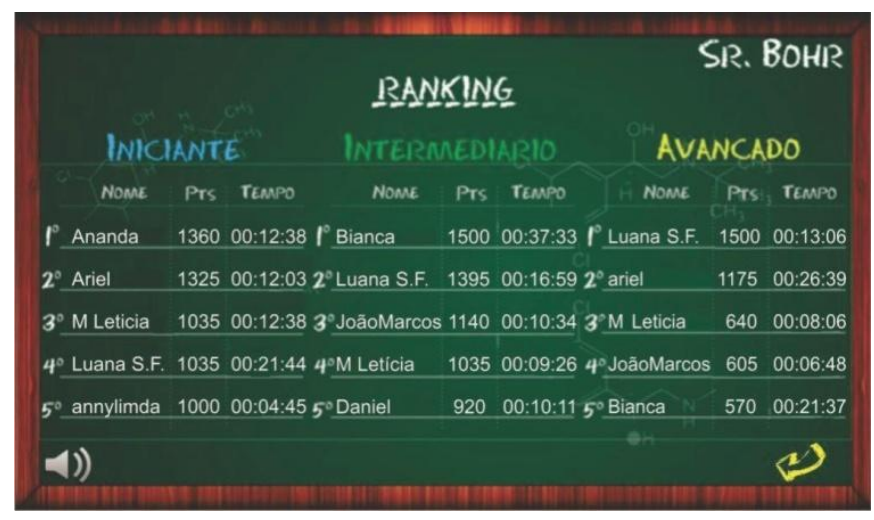

Figura 3. Ranking dos discentes Fonte. Próprio autor

Durante a realização do experimento com os discentes, pôde-se observar o entusiasmo, a curiosidade e o interesse dos mesmos. As respostas ao questionário corroboram com esta observação, que é também ratificada pelos dados armazenados no SGBD, que mostram que os discentes realizaram várias tentativas de responder uma mesma questão, e jogaram mais de uma rodada no mesmo nível, objetivando alcançar uma maior pontuação, e a inclusão do seu nome no ranking. Isto indica que os discentes se sentiram motivados, e que a competitividade também foi estimulada. Esta característica pode configurar-se como aliada importante ao processo de ensinoaprendizagem, tendo em vista que a partir do momento que o discente é desafiado, encontra uma motivação própria para buscar respostas às perguntas presentes no jogo. A partir disso, o jogador torna-se o maior interessado em aprender, e o aprendizado ganha maior sentido para o mesmo. Assim, numa disputa com colegas, como num jogo convencional, é possível assimilar conteúdos de química, de maneira divertida.

As respostas do questionário indicaram que Sr. Bohr foi bem aceito pelos discentes, no qual todos consideraram como interessante e muito prazerosa a possibilidade de obter conhecimento jogando. Outro ponto interessante foram as respostas em relação ao nível das questões do jogo, no qual 53\% e 47\% classificaramnas, respectivamente, como difíceis e intermediárias. No critério motivação para responder todas as questões (pergunta específica 1), 47\%, 24\% e 12\% responderam, respectivamente, como respostas os critérios 4,5 e 3 . Por sua vez, a maioria dos discentes $(71 \%)$ concordou totalmente (critério 5) que o jogo é desafiador (pergunta específica 2). Na Figura 4 é possível observar as respostas dos discentes para todas as perguntas específicas.

No Momento 2, os docentes afirmaram que o jogo tem conteúdo relevante e design atraente. É importante ressaltar que $80 \%$ e $20 \%$ classificaram, respectivamente, como critério 5 e 3 quando lhes foi perguntado se gostaria de utilizar o jogo como uma ferramenta no processo ensino-aprendizagem. Ademais, destaca-se que todos os docentes participantes responderam que gostariam de acrescentar suas próprias questões 
na base de dados do jogo. A importância da utilização do jogo como atividade lúdica e ao mesmo tempo como ferramenta de auxílio ao processo de ensino foi bem avaliada pelos docentes, no qual $75 \%$ classificaram como critério 5 e $25 \%$ como 3 . Isso mostra que os docentes reconhecem a importância de utilizar este tipo de ferramenta no processo de ensino-aprendizagem.

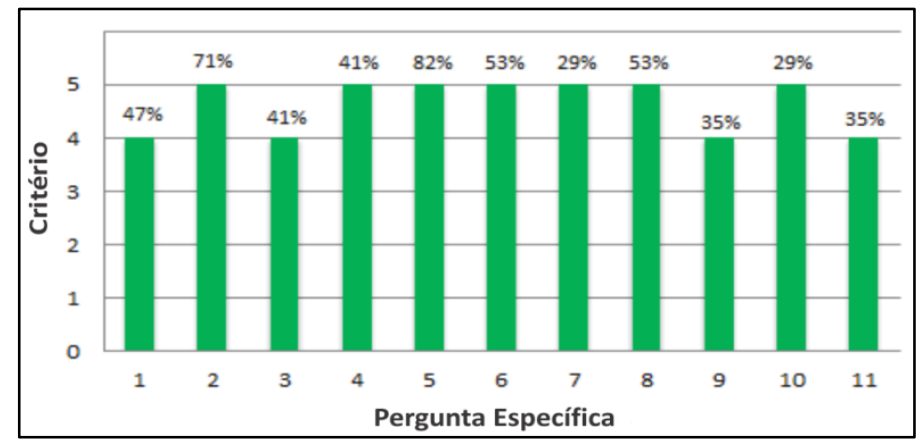

Figura 4. Respostas específicas dos discentes Fonte. Próprio autor

\section{Conclusões e Trabalhos Futuros}

O software educacional Sr. Bohr tem como objetivo oferecer ao usuário um desafio do tipo perguntas e respostas (enigma/pista) relacionadas aos conteúdos de química e aspectos do cotidiano. Por meio de experimentos realizados com discentes e docentes, observou-se que o Sr. Bohr possui boa aceitabilidade como ferramenta lúdica para o processo ensino-aprendizagem. Conclui-se, portanto, que o Sr. Bohr é um software promissor no sentido de auxiliar o docente no ensino de química de forma lúdica, possibilitando ao discente assimilar o conteúdo da disciplina e estabelecer relações com o cotidiano, e aprender por meio do desafio, da recompensa e dos estímulos visuais.

Os enigmas desenvolvidos como temas geradores centralizam a discussão acerca de um tema principal, aos quais todas as pistas estão interligadas, de forma a relacionar os conteúdos da química com assuntos do cotidiano dos discentes. Desta maneira a contextualização do conhecimento foi realizada valorizando a vivência do discente, já que tópicos do dia a dia estão presentes no enigma e os conteúdos da disciplina que são relacionadas a esses tópicos, nas pistas. Com a contextualização, os discentes podem perceber as relações existentes entre a teoria estudada e as situações de seu cotidiano e, assim, compreender a importância do estudo de tais conteúdos.

Como trabalhos futuros, pretende-se expandir a utilização do software a fim de permitir também a alimentação da base dados com temas geradores mais abrangentes, que possibilitem a discussão de conteúdos não apenas de química, mas também de outras áreas do conhecimento, como física e biologia, numa perspectiva interdisciplinar, conferindo ao jogo maior potencial educativo. Ademais, pretende-se disponibilizar o software em repositórios educacionais livres, permitindo ao docente a inserção dinâmica de novas questões, atendendo ao desejo manifestado pelos docentes, em reposta ao questionário, de poder inserir suas próprias questões no jogo.

\section{Agradecimentos}

Os autores agradecem o apoio financeiro das agências de fomento à pesquisa do Brasil FAPESB/PIBIC e CAPES/PIBID, e a participação de docentes e discentes que contribuíram positivamente com a realização do experimento. 


\section{Referências}

1. Souza, I.M.A. and Souza, L.V.A. (2010) O Uso da Tecnologia como Facilitadora da Aprendizagem do Aluno na Escola. Revista Fórum Identidades, 8, 4, 127-142.

2. Falkembach, G.A.M. (2013) O Lúdico e os Jogos Educacionais. Centro Interdisciplinar de Novas Tecnologias na Educação - UFRGS, RS.

3. Redação Mais Comunidade. (2012) Especialistas Avaliam a Importância dos Jogos na Educação, http://goo.gl/cuJPs4.

4. Guimarães, O.M. (2012) Atividades Lúdicas no Ensino de Química. Experimentação e Atividades Lúdicas. pages 1-5.

5. Guimarães, A.R. and Robaina, J.V.L. (2012) Ciências Através do Lúdico: Brincando e Aprendendo. In Simpósio Nacional de Ensino de Ciência e Tecnologia. pp. 1-11.

6. Eichler, M. and Pino, J.C.D. (2000) Carbópolis, um Software para Educação Química. Química Nova na Escola, 11, 10-12.

7. Souza, M.P. et al. (2004) Desenvolvimento e Aplicação de um Software como Ferramenta Motivadora no Processo Ensino-Aprendizagem de Química. In XV SBIE. pp. 487-496.

8. Machado, A.F.V. et al. (2011) Uma Proposta de Jogo Educacional 3D com Questões Didáticas. In XXII SBIE - XVII WIE. pp. 620-629.

9. Silva, D.L.M. and Rebouças, A.D.D.S. (2011) Myquímica - Um Jogo para Auxiliar no Ensino-Aprendizagem das Nomenclaturas Químicas. In XXII SBIE - XVII WIE. pp. 1858-1862.

10. Zanon, D.A.V., Guerreiro, M.A.S. and Oliveira, R.C. (2008) Jogo Didático Ludo Químico para o Ensino de Nomenclatura dos Compostos Orgânicos: Projeto, Produção, Aplicação e Avaliação. Ciências \& Cognição, 13, 78-81.

11. Moreira, F.B.F. et al. (2012) Bingo Químico: Uma Atividade Lúdica Envolvendo Fórmulas e Nomenclaturas dos Compostos. HOLOS, 6, 28, 124-130.

12. Souza, H.Y.S. and Silva, C.K. (2012) Dados Orgânicos: Um Jogo Didático no Ensino de Química. HOLOS, 3, 28, 107-121.

13. Santos, A.F. et al. (2008) Trilha da Química, uma Inovação no Processo EnsinoAprendizagem. In XIV Encontro Nacional de Ensino de Química. pp. 1.

14. Oliveira, J.C., Moreira, B.C.T. and Carvalho, M.F.A. (2011) Baralho Ácido-Base: Estudo Comparativo da Força de Ácidos e Bases Inorgânicos. In IX Simpósio Brasileiro de Educação Química. pp. 1-2.

15. Lucena, G.L. and Azevedo, M.S. (2012) QUIZmica: Um Jogo Virtual Auxiliando o Ensino de Química. Revista Tecnologias na Educação, 7, 4, 1-11.

16. SILVA, M.S. (2011) HTML5: A Linguagem de Marcação do Futuro. Novatec, São Paulo.

17. W3C. (2010) XML Technology, http://www.w3.org/standards/xml/.

18. Dillon, R. (2014) HTML5 Game Development from the Ground Up with Construct 2. CRC Press, Florida.

19. The Inkscape Team. (2014) Inkscape - Draw Freely, www.inkscape.org/pt.

20. Soares, W. (2010) PHP 5: Conceitos, Programação e Integração com Banco de Dados. Érica, São Paulo.

21. Milani, A. (2006) MySQL: Guia do Programador. Novatec, São Paulo.

22. Coquetel. (2013) Jogo Online Roda das Esmeraldas, http://coquetel.uol.com.br/jogos.

23. Carvalho, V.L., Matos, P.F. and Santos, W.C. (2013) Uma Proposta de um Software Educativo para o Ensino de Química. In VIII CONGRESSO NORTE NORDESTE DE PESQUISA E INOVAÇÃO. pp. 1-8. 